\section{Kristian Valdemar Hansen: en personlighed inden for dansk revy $i$ tiden 1909-28}

\author{
Aflektor Allan Røder
}

$\mathrm{V}$ aldemar Hansen hed en københavnsk forfatter, der for godt 80 år siden var et kendt navn inden for dansk revy.

Når man taler om revy, som den var før i tiden, tænker de fleste på Poul Henningsen og Liva Weel og Cooptimisterne, men også før dem var der gang i den på de skrå brædder, og en af dem, der hører med til historien om dansk revy før 1930 'erne, er Valdemar Hansen.

Egentlig hed han Kristian Valdemar Hansen og var født 13. juli 1883 i København. Han var den yngste af en børneflok på syv.

Han var fire år, da hans far døde.

Faren havde arbejdet som gårdskarl, og familien havde altid siddet hårdt i det. Efter hans død måtte moren ernære familien ved håndarbejde samt en daler, som hun tjente ved at bære en posttaske fra Christianshavns Torv til posthuset i Strandgade, - dagvognen fra Dragør kørte kun til torvet.

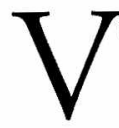

aldemar Hansen begyndte som skuespiller på en af Københavns mere upåagtede scener. Som ung havde han engagement ved det lille etablissement, der blev kaldt Arbejdernes Teater. Hans succes på de skrå brædder var begrænset, men heldigvis havde han andre muligheder. Og allerede i 1902 skrev han
Tornerose, et drama i fire akter, der blev opført Anden Juledag på Arbejdernes Teater på Kløvermarksvej. Han spillede selv med i stykket, der absolut må siges at høre til i den dystre afdeling af hans produktion. Hovedpersonen, en murerdatter, der tilbedes af en ung digter, ender med at konkludere, at det hele er håbløst, og skyder sig en kugle for panden. Social-Demokraten, der som arbejdernes avis følte en vis forpligtigelse til at følge med i tildragelserne på Kløvermarksvej, havde sin udsendte medarbejder med ved premieren. Medarbejderen var ikke begejstret. Han noterede sig, at forestillingen var lovlig teatralsk, med mange store ord, og at resultatet i betænkelig grad nærmede sig det melodramatiske. Men som god socialdemokrat endte han med denne betragtning: „For Resten er Folket selv den rette Dommer, og Folket var særdeles tilfreds baade med Skuespillet og med Udførelsen: mange Fremkaldelser efter Tæppets Fald og tilsidst et længe Leve for Forfatteren. "(1) Efter forestillingen var der åbent i restaurationen og dans til klokken tre om natten, så folk kunne slappe af efter de kulturelle input.

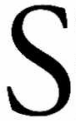
åledes opmuntret gik den 19-årige forfatter og skuespiller straks i gang med sit næste værk. Det blev opført året efter og kom til at hedde Havnet. Det blev sat op i nogle provinsbyer og havde en vis succes, hvorefter det kom til Arbejdernes Teater, denne gang scenen på Enghavevej, hvor det åbnede vintersæsonen i oktober 1903. Ligesom $\sin$ forgænger var det meget dramatisk. En ung mand, Max, kommer i huset hos en aldrende oberst og en meget ung oberstinde. De to unge har en affære, og obersten hævner sig ved at føre Max ud i spillegæld og, for at gøre en lang historie kort, ender Max med at begå selvmord. Social-Demokratens anmelder, den samme 


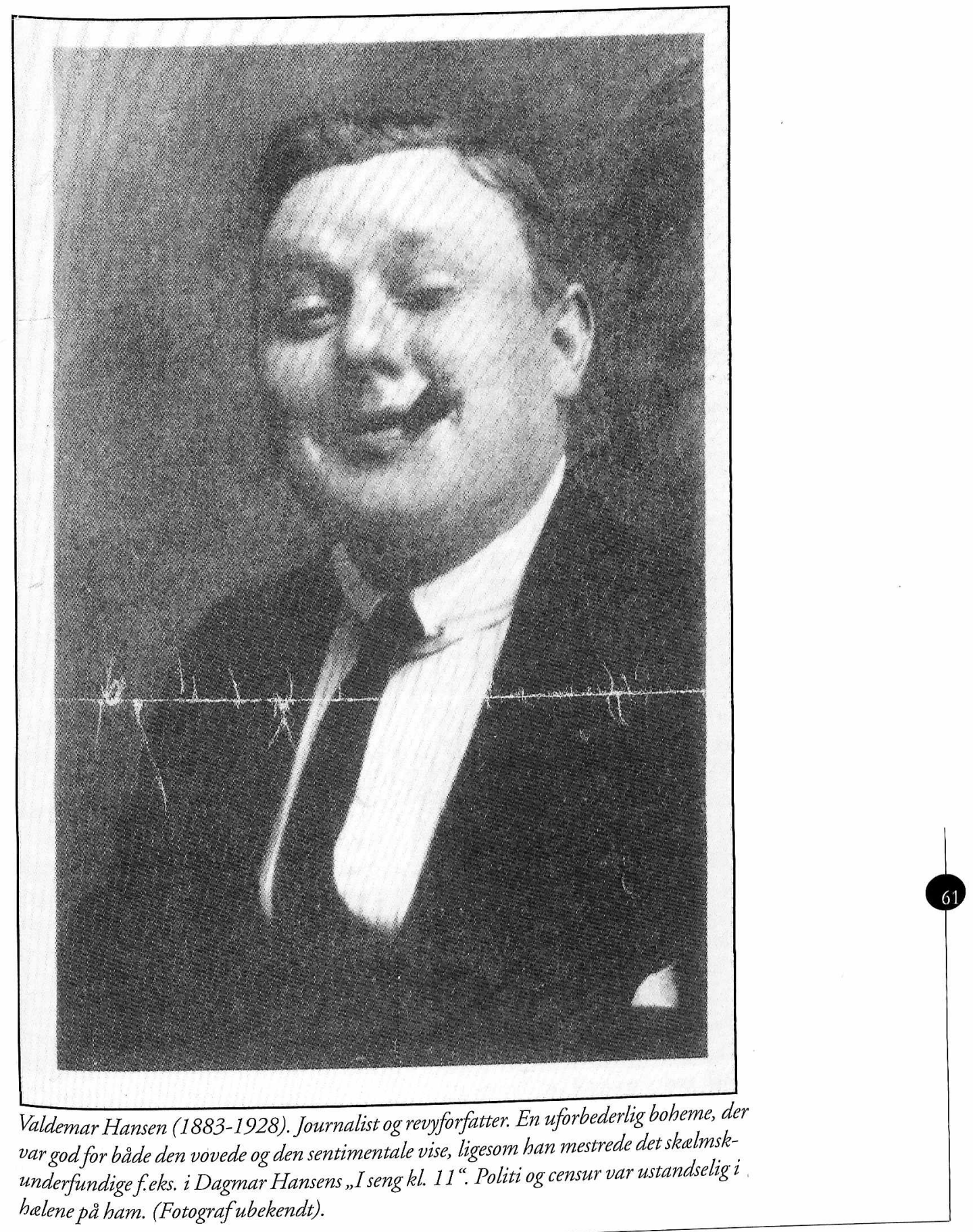


som sidst, rykkede ud igen for at vurdere den unge mands nye produkt og var stadig ikke tilfreds; der var enkeltheder, der ikke forekom ham videre troværdige. Men han konkluderede: „Alligevel er der meget stemningsfuldt og smukt i Stykket, og det blev Akt efter Akt modtaget med stærkt Bifald, og da Tæppet faldt for den sidste tragiske Scene, blev det klappet op igen en 5-6 Gange." (2)

Selv når man tager højde for de venner og familiemedlemmer, som den unge forfatter muligvis havde fået placeret i det lille teater, kunne der ikke være tvivl om, at han kunne notere sig endnu en publikumssucces - og endnu en skeptisk modtagelse hos arbejderavisens anmelder.

Det var et forhold, der fulgte ham gennem hele livet. Folk kunne lide, hvad han skrev, mens anmeldere og litteraturkritikere som regel var mere skeptiske.

Hevnet blev hans sidste forsøg inden for det (meget) seriøse, og hans skuespillerkarriere er formodentlig også sluttet ret kort tid efter. De selvbiografiske elementer anes i en senere monolog, hvor der fortælles: „Jeg skal sige Dem - jeg havde været Skuespiller i flere Aar - altsaa i Provinsen, - og jeg havde gjort vældig Lykke som Elsker - jeg var nemlig meget smuk dengang - det er sgu sandt - ja, man kan maaske ikke se det nu - men det er autentisk. - Jeg havde gjort vældig Lykke - jeg havde faaet Buketter baade i Nibe og Løgstør. "(3)

A llerede mens han skrev på skuespillene, lavede han også ting $\mathrm{i}$ helt andre genrer. Han flirtede en smule med journalistikken (senere i livet kaldte han sig altid journalist, hvis nogen spurgte efter hans borgerlige erhverv), - og til Vennelyst Varieté-Blad, som hans svoger var redaktør for, skrev han viser og vers.

De viser og vers var det, som han til sidst valgte at satse på.

I 1909 fik „Valde" kombineret visen med teatret på en måde, der skulle vise sig at ligge godt for ham. Enkelte af hans viser var af den alvorlige type, - nogle af hans mere entusiastiske tilhængere kaldte ham senere endda for "den danske Søderberg. " ${ }^{\text {(4) }}$ Men de allerfleste af hans produkter var enkle og muntre historier. Han fik nu fire sange med i Tivoli-Varieteen, senere kendt som Apolloteatret. De optrædende her havde oprindelig mest været sangerinder, men en ny direktør havde sørget for, at hovedvægten efterhånden var blevet lagt på revyer og farcer. Med dette mål for øje havde han i 1905 ansat sküespilleren Carl Fischer. ${ }^{(5)}$

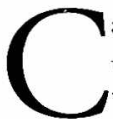

arl Fischer blev med årene en vældig populær visesanger, og Valdemar Hansen var manden bag et par af Fischers kendte viser, nemlig „Saa sku' De se ham komme op!" (TivoliVarieteen i 1912) og „Brændt a“" (også kendt som „Saa var det hele ødelagt", fra Tivoli-Varieteen i 1915). ${ }^{(6)}$

Især den sidstnævnte vise blev en succes og blev et gennembrud for Carl Fischer. Visen „blev årets store landeplage, blev solgt i titusindvis på postkort og som noder i musikhandelerne, og havde man haft grammofoner og dansktop den gang, havde det været årets sikreste vinder. "(7) Ud over Fischer har også visesangerne Hans W. Petersen og Erik Paaske siden haft sangen på deres repertoire og indspillet den på plade. ${ }^{(8)}$ Den populære vise handlede, ligesom Valdemar Hansens tidlige teaterstykker, om kærlighed og de problemer, som den slags kan føre til; men selv om der kan spores ligheder i emnevalg, er behandlingen 


\section{Stella. \\ Mell.: Anna Marglethe.}

Paa Gaden Stella gik, hvor lose Fugle holder til,

Hun havde aldrig ejet Sko med hele Saaler til,

Men Stella havde et Par glade Ojne, morkeblaa,

Saa rod en Mund, saa sød som hun jeg aldrig nogen saa.

Blink var der allid i Gjet

Hyor Stella satte sin Fod,

Straalende, lyst og formogjet,

Som ikke En stod imod.

Stella var ikke anstrendig,

Hun fejl om Moralen sig brod,

Men det var ej heller nodvendig.

Naar hun var saa ung og saa sod.

Og Stella fik en Ven, ja hun fik to i Overmod,

Den Ene gay hun al sin Karlighed - sit Hjarteblod,

Den Anden han fik Kys med hyide Arme om sin Hals,

Men hendes unge krerlighed var derfor ej til Fals.

Blink var dor altid i Ojet,

Hyor Stella satte sin Fod,

Straalende lyst og fornojet,

Som ikke En stod imod.

Stella var ikke anstæendig,

Men elske for Hummer og Skum,

Nej det var dog ilke nødvendig,

Naar Fyren var flabet og dum.

En Nat kom Stella ikke hjem, det sker i store Byer,

Det er den sidste triste Akt paa kønne Eventyr.

Da Stella kom tilbage, var hun bleg, men elegant,

Og Silken, hvilken Knittren - alt hos Stella var pikant.

Men Blink var der aldrig i ojet,

Det Blink, som vi alle forstod.

Straalende lyst og fornøjet,

Som ikke En stod imod.

Stella var ikke anstæendig,

Nu er til Doden hum træt.

Var det monstro saa nødvendig

At fange den lille Grisette.

Valdemar Hansen.

Visen "Stella" af Valdemar Hansen er trykt i Vennelyst Varieté-Blad (november 1903).

Publikationen beskriver sig selv som bladet med de morsomme, og interessante biografier, interviews og billeder afforskellige artister, sange, anekdoter og humoristiske fortellinger fra teater-og varieté-livet. (Foto: Det Kongelige Bibliotek). 
af stoffet noget anderledes end i dramaerne:

„Jeg til stævnemøde var sat ved Peter Lieps

hus, der nu er brændt, og bar mit pæne røde slips, men alligevel så ga’ pigen mig sit nej, det blev jeg fortvivlet a', så jeg gik og skreg:

Jeg mig skyder med det samme, jeg til raseri er bragt, men så ku' jeg ikke ramme så var det hele ødelagt. ${ }^{(9)}$

Kærlighed var også temaet i „Saa sku' De se ham komme op!", hvor et af versene lød:

„Den gamle Madsen ikke vil staa op, som el's han plejer, men da hans Kone ligge vil

og lave Narrestreger, saa sku' De se ham komme op, saa sku' De se ham komme op, lige saa højt han ku' komme. “(10)

Også den umådelig populære sangerinde Dagmar Hansen fremførte, undertiden kun iført det allermest nødvendige, et par af Valdemar Hansens viser, heriblandt "Jeg skriger hvis han gør'et og han ikke gør'et godt" ${ }^{\text {“(11) }}$ og „Gaa i Seng Kl. 11."(12)

Det tog ikke Valdemar Hansen lang tid at etablere sig som en af tidens mere vovede forfattere. Allerede ved hans allerførste revy kunne man ved en af hans viser („Lattervise“) finde påskriften: „Efter Henstilling fra Censor synges 2det Vers ikke i Tivoli Varieté. "(13) Herefter var der noget at leve op til med de følgende viser, og op gennem årene fortsatte han med at gå lige til stregen, og nogle gange lidt over. Politi og censur holdt altid et vågent øje med ham. ${ }^{(14)}$

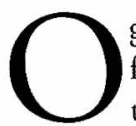
gså ved Thalia-Revyen i 1920 var flere af hans sange lige på grænsen til det utilladelige. ${ }^{(15)}$ Men han

behøvede ikke at tage sig så meget af kritikken det år, fordi han nu - efter i alt at have leveret viser til godt 25 forskellige revyer, varieteer, syngestykker og komedier, som oftest Thalia, Charlottenlund Revyen (= Over Stalden), Fønix Teatret, Vinterpaladset og White Star, - havde en ny slags aftager. Det var tidsskriftet Exlex, - et fællesnordisk satirisk organ, hvor han kom i selskab med forfattere som Hans Hartvig Seedorf, Tom Kristensen, Johannes Buchholtz, Johannes V. Jensen, Martin Andersen Nexø og ikke mindst Storm Petersen, der kom til at sætte sit personlige præg på tidsskriftet med sine karakteristiske tegninger og fortællinger.

Til dette organ leverede Valdemar Hansen i alt nitten upolitiske viser om kærlighed, de fleste i foråret og sommeren 1920. En af dem var „Sømandsknuden“, der senere blev til „Fru Grete“ i Lystige viser. (16)

\section{Over halvdelen af Valdemar}

Hansens viser i Exlex er udformet som korte teaterstykker, med replikker og regibemærkninger. Som f.eks. i „Og saa vid're. Komedie i 3 smaa Akter", hvor der først er en beskrivelse af de tre medvirkende - en hotelvært, en værtinde og en rejsende -, derefter, i begyndelsen af første akt, en beskrivelse af situationen: hotelværten har fâet telegram fra en gammel ven og rejsende, som beder om et værelse og lidt kvindeligt selskab („og så videre“), - og derefter dialog med værtinden, der raser over den umoralske ven og forgæves forlanger, at værten giver sin ven en overhaling. Her fra slutnin- 
gen af andet akt:

„Fruen (i ædel Harme):

Naa, vil Du ikke - saa skal jeg

- det manglede da bare.

3. Akt.

(iler op).

Hotellet. Værten staar bag

Buffeten, ængstelig afventende Resultatet af sin Kones Sendefærd. Den Rejsende kommer ned, glad og oprømt, gaar straalende hen til Værten.

Værten (beroliget):

Naa, Gudskelov Du ej er vred, jeg frygtede, som Fanden.

Den Rejsende (forbavset):

Hvad - vred paa Dig - det mangled' blot,

Du er som ingen anden,

Du glemmer ej en gammel Ven, det tog man aldrig fejl $i$,

(hemmelighedsfuldt og smilende) der var jo først en Masse Vrøvl, men næh, hvor var hun dejlig. “(17)

$\mathrm{F}$ å måneder senere udkom det sidste nummer af Exlex. Valdemar Hansen koncentrerede sig nu igen om revyerne, men begyndte også at samle materiale til en lille bog med nogle af hans bedste monologer. Den udkom i 1924 og indeholdt seks historier, hvoraf flere allerede havde været afprøvet på scenen, - samt en parodi på et digt af Jeppe Aakjær:

„Jeg slaar min Harpe til Rugvippens Sang, til Havrens klingende Bjælder, det har den samme vemodige Klang som Koens Brøl, naar den kæller.

Skønt er det at se, naar Hø staar i Stak og Frøen den kvækker i Kæret, og se, naar de Unge de ligger i Snak i Høet med Bagen i Vejret. “(18)
I monologerne var kærlighed igen et af de gennemgående temaer. Det var dog ikke ægteskabet, han reklamerede for. Hans kommentar til det var:

„Kære Venner, ægteskabet, det er en skøn Institution, men desværre viser det sig saa sørgeligt, at de respektive Mænd og Koner er deres respektive Koner og Mænd utro. Og det er stygt, hvor behageligt det paa den anden Side ka' være - for det er det, Fanden knage mig, det ka' der ikke være Tale om andet. "(19)

\section{Somandsknuden.}

1 Gownen lad tor Anken en udenlandsk Kopvet, hoon Officererne fik bust at danse -. Grosserens lyse inger. der ev smilende koket, blev ogsaa inviteret med om Bond, af eri Kadet Dej, danse, danse aldrig mete standse.

5un kommer bjem om Datten, og det ep i Fpeil,

i tusind glade Doømme

om Radetten -

it hine Silketcepper vil bun til at søge 5oil, da siger hendes litle Kammerpige, med et Smil: Daa. Enokneti bat nok voret paa Korvetten,

Eorbauset Inger soutter sig paa sin "Dygmation",

- Guordan kan Da dog vide det. Gertoude.

- Jo, det kan jeg da sagtens,

for da jeg med noensom baand forsøgte paa at lose

Enokenens intime Baand, saa var de bundet thed en Somandsknude.

Vafdemar Hansen.

"Somandsknuden" af Valdemar Hansen

udkom i Exlex 13. marts 1920. (Foto:

Det Kongelige Bibliotek). 
$\mathrm{R}$ eligiøse skikke i det hele taget samt kirken og dens forkyndere havde han et noget anstrengt forhold til. Han var blevet meldt ud af Folkekirken allerede i 1918, og i hans tekster er det ikke vanskeligt at finde eksempler på hans holdning:

,...ham Tevelogen, han var heller itte rigtig klog: han vilde omvende Maren - vores Pige - ved det, at han havde hørt, at hun havde haft lidt Kjæreste og Film - men jeg tror nok, at det var hende der omvendte ham tilsidst, for han sad ovre hos hende hele Natten, og jeg tror itte de sang Salmer hele Tiden." (20)

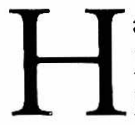
an havde nu rundet de fyrre og havde sin bedste tid bag sig. $\mathrm{Og}$ hans sidste år blev vanskelige.

På det private plan stødte der alvorlige problemer til, da hans mangeårige ægteskab med en tidligere korpige fra Scala blev opløst, og han måtte flytte fra en god lejlighed over til sin ugifte søster i en kælder.

Dertil kom, at der var blevet længere mellem hans engagementer, - der kunne nu efterhånden gå år imellem. I 1927 var der en revy, hvor han igen stod som tekstforfatteren. Men det blev hans sidste. Forestillingen blev spillet på White Star ude på Amagerbro og vakte ingen større opsigt.

Samme år optrådte Liva Weel på Scala, og Ludvig Brandstrups og Mogens Dams sommerrevy, med Co-optimisterne og med musik af Kai Normann Andersen, gik over brædderne på Allé Teatret. En ny tid var begyndt inden for dansk revy.

I den ny tids revy var det, som om der ikke rigtig var plads til Valdemar Hansen og den stil, som han skrev i. Nogle syntes, at han var for fræk, andre måske, at han ikke rigtig havde andet at byde på end en vældig interesse for jordelivets goder.

Det må da også indrømmes, at "Valde" gik ind for at nyde livet i fulde drag, især måske kærligheden. Men derudover havde han også sans for andre behageligheder, - deriblandt cigarer. Man så ham sjældent uden. Også på portrætter, hvor han skulle tage sig ud, kom cigaren med; den blev nærmest et varemærke for ham. ${ }^{(21)} \mathrm{Han}$ var også en tilhænger af bordets glæder og blev med tiden temmelig omfangsrig. $\mathrm{Og}$ endelig blev han kendt for at drikke på en måde, der skaffede ham tilnavnet „DrukValde" på halsen. ${ }^{(22)}$

Hvilken indflydelse hans energiske livsførelse havde på ham, er svært at sige. Men faktum er, at han døde i en alder af kun 44 år.

Han blev aldrig en af landets store forfattere. Men et par af hans viser bliver da stadig sunget, og selvom han ikke var en af dem, der loddede nye dybder $\mathrm{i}$ menneskesindet, bidrog han med sine sange til at gøre hverdagen lidt muntrere for mange tusinder af sine samtidige. Og det er måske lige så meget værd. 
Noter:

1. Social-Demokraten, 28/12 1902, s. 2.

2. Social-Demokraten, 6/10 1903, s. 2 .

3. Valdemar Hansen: Niels Pinds komiske Foredrag og Historier (J. L. Wulff's Forlag, 1924), s. 5.

4. Vore Herrer, 7/3 1918, „Vore kære Venner Revyforfatterne - uden Retouche", s. 18.

5. Bent Zinglersen: Kobenhavnerliv - der blev borte (Forlaget Børge Binderup, 1973), s. 81-82.

6. Bent Zinglersen og Lystige viser, bind 6 (red. af Else Larsen og Bo Bramsen, Politikens Forlag,1985), er enige om 1910; men Emil Marott (Dansk revy, bind 3, Borgen, 1991) peger entydigt og mere veldokumenteret på 1915. Jvf. Den Store Danske Encyklopeedi, bind 6 (Danmarks Nationalleksikon, 1996), om Carl Fischer, og Erik Hvidt: Politikens Revyhistorie (Politiken, 1981), s. 131.

7. Bent Zinglersen: Kobenhavnerliv - der blev borte (Forlaget Børge Binderup, 1973), s. 82.

8. Emil Marott: Dansk revy, bind 3 (Borgen, 1991), s. 128.

9. Efter Lystige viser, bind 6 (red. af Else Larsen og Bo Bramsen, Politikens Forlag, 1985), s. 32 .

10. „Originale Københavnerviser", fra Aug. Halck's Musikhandel, nummer 79. Revyog morskabsmuseet.

11. „Originale Københavnerviser", fra Aug. Halck's Musikhandel, nummer 101. Revyog morskabsmuseet.

12. Emil Marott: Dansk revy, bind 2 (Borgen, 1991), s. 646.

13. „Originale Københavnerviser", fra Aug. Halck's Musikhandel, nummer 14. Revyog morskabsmuseet.

14. Emil Marott: Dansk revy. Bind 1 (Borgen, 1991), s. 240, 320. Bind 2, s. 646.

15. Emil Marott: Dansk revy. Bind 2 (Borgen, 1991), s. 618-619. Bind 3, s. 188-189.

16. Exlex, $13 / 31920$, s. 122.

17. Exlex, $10 / 41920$, s. 172.

18. Valdemar Hansen: Niels Pinds komiske
Foredrag og Historier (J. L. Wulff's Forlag, 1924), s. 32.

19. Valdemar Hansen: Niels Pinds komiske Foredrag og Historier (J. L. Wulff's Forlag, 1924), s. 30.

20. Valdemar Hansen: Niels Pinds komiske Foredrag og Historier (J. L. Wulff's Forlag, 1924), s. 19.

21. Emil Marott: Dansk revy, bind 2 (Borgen, 1991), s. 645-646.

22. Chr. Glatved: Provinsens sommerrevyer (Berlingske Forlag, 1979), s. 148. 
